5 Sakati NO, Nyhan WL. Congenital cutis laxa and osteoporosis. Am J Dis Child 1983;137:452-4.

${ }^{6}$ Patton MA, Tolmie J, Ruthnum P, Bamforth S, Baraitser M, Pembrey M. Congenital cutis laxa with retardation of growth and development. J Med Genet 1987;24:556-61.
Correspondence and requests for reprints to $\mathrm{Dr}$ A G W Hunter, Division of Genetics, Children's Hospital of Eastern Ontario, 401 Smyth Road, Ottawa, Ontario, Canada K1H 8L1.

\title{
Achondroplasia in sibs of normal parents
}

\author{
N PHILIP, M AUGER, J F MATTEI, AND F GIRAUD \\ Centre de Génétique Médicale et INSERM U242, Hôpital d'Enfants de la Timone, Boulevard Jean Moulin, \\ 13385 Marseille Cedex 5, France.
}

SUMmARY A new case of recurrent achondroplasia in sibs of normal parents is reported. Two sisters and a half sister were affected. Various mechanisms can be postulated to account for unexpected recurrence of achondroplasia in the same sibship. Germinal mosaicism and unstable premutation are discussed here.

Achondroplasia is the commonest type of short limbed dwarfism. Dominant inheritance is clearly established and sporadic cases are the result of new mutations. Three families with more than one affected sib and normal parents have been previously reported. In the present report, a normal father had three achondroplastic daughters from two different mothers.

\section{Case reports}

The family pedigree is shown in fig 1 . Case 1 (II.1) was born in 1975 to a healthy, unrelated 17 year old mother and 30 year old father. Birth length was 47.5

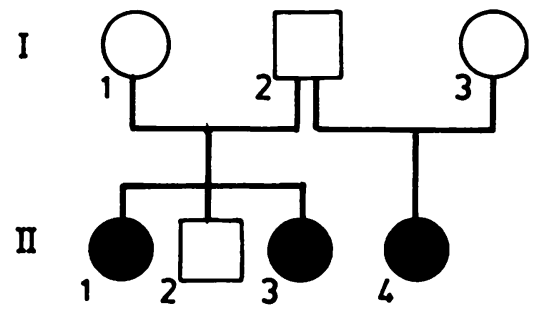

FIG 1 Pedigree of family.

Received for publication 5 January 1988

Revised version accepted for publication 24 February 1988. $\mathrm{cm}$ and birth weight $3030 \mathrm{~g}$. Achondroplasia with rhizomelic shortening of the limbs and macrocephaly was suspected at birth and $x$ ray films of the skeleton confirmed the diagnosis. When examined for the second time, the girl was 12 years old and 116 cm tall. Psychomotor development was normal. Clinical and radiological features were typical of achondroplasia. A normal boy was born in 1977 .

Case 2 (II.3), born in 1981, is the sister of case 1. The diagnosis of achondroplasia was immediately evident. At five years of age, she was $85 \mathrm{~cm}$ tall.

Both parents were examined. Clinical and radiological examination was normal with no stigmata of achondroplasia.

Case 3 (II.4) is the half sister of cases 1 and 2, with

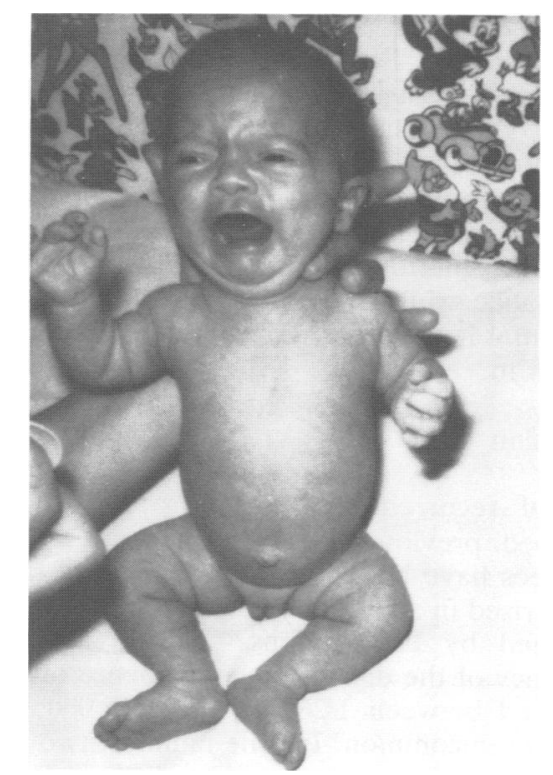

FIG 2 Case 3 at birth. 


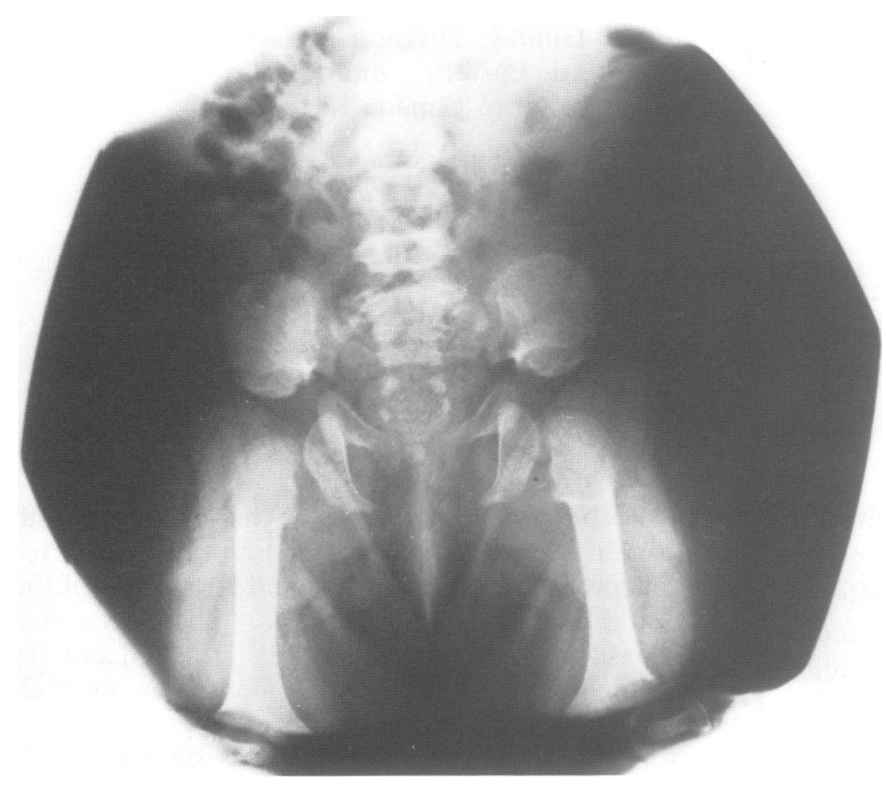

FIG 3 Pelvis of case 3.

the same father and a healthy, unrelated young mother. Genetic counselling was requested at the beginning of the pregnancy and a thorough echographic survey was proposed. Echographic measurements of the femur remained normal until the sixth month when the curve began to decrease. Femoral length was $47 \mathrm{~mm}$ at the $32 \mathrm{nd}$ week (5th centile for gestational age). Fetal $x$ ray showed short femur and humerus, frontal bossing, and metaphyseal flaring of the long bones, suggesting the diagnosis of achondroplasia. When the child was born, the diagnosis was confirmed (fig 2). Birth length was 42 $\mathrm{cm}$ and weight $2680 \mathrm{~g}$. Fig 3 shows an $x$ ray of the pelvis at six months of age showing the typical aspect of the iliac wings.

Parental heights are: I.1 $1.63 \mathrm{~m}, \mathrm{I} .21 .66 \mathrm{~m}$, and I.3 $1.64 \mathrm{~m}$.

\section{Discussion}

Familial recurrence of achondroplasia has been described previously and, to our knowledge, 12 pedigrees have been reported. Eleven of them are summarised in a review by Opitz ${ }^{1}$ and one has been published by Fitzsimmons. ${ }^{2}$ In the light of the frequency of the disorder, the incidence of which is estimated between $1 / 26000$ and $1 / 35000$, familial cases are uncommon. In nine families, two more or less distant relatives were affected, the relationship varying from first cousins to second cousins once removed. In two families, one of the affected probands had similarly affected children. In the lasto three pedigrees several subjects were affected in the? same sibship. Bowen ${ }^{3}$ reported two affected sisters with normal parents, one of whom had an affected child. Opitz ${ }^{1}$ reported a family where normal parents had an achondroplastic son and daughter. The case of Fryns et $\mathrm{l}^{4}$ with three affected sisters resembles the present report. Several explanations have been proposed to account for these phenomena. First, the hypothesis of two different mutational events is supported by Reiser et al. ${ }^{5}$ This hypothesis cannot be excluded when distantly related subjects are affected, but is unlikely when achondroplasia occurs in three sibs.

Regarding the first case involving sibs, Fryns et $\mathrm{l}^{4}$ suggested germinal mosaicism. This theory is attractive but one could expect such recurrences for other fully penetrant mutations. Recently, Allanson ${ }^{6}$ reported two sisters with Apert's syndrome born to normal parents. Hall et $a l^{7}$ suggested that this mechanism should be considered when other autosomal dominant conditions such as pseudoachondroplasia or tuberous sclerosis ${ }^{8}$ occur in sibs of normal parents.

Opitz, ${ }^{1}$ in his review, suggested that an unstable premutation with reduced penetrance or phenotrance would be the best way of explaining both phenomena.

Apart from the theoretical aspect, the two hypo- 
theses have very different implications in genetic counselling. If the cause is germinal mosaicism, genetic counselling is reassuring for all the healthy members of the family except for the father of the three affected girls. If the hypothesis of an unstable premutation with reduced phenotrance is accepted, then all the family members are concerned. In the present family, the risk for the healthy brother (II.2) of having an achondroplastic child is negligible on the first hypothesis and very high on the second one.

\section{References}

${ }^{1}$ Opitz JM. Unstable premutation in achondroplasia. Penetrance versus phenotrance. Am J Med Genet 1984;19:251-4.

${ }^{2}$ Fitzsimmons JS. Brief clinical report. Familial recurrence of achondroplasia. Am J Med Genet 1985;22:609-13.
3 Bowen P. Achondroplasia in two sisters with normal parents. Birth Defects 1974;10(12):31-6.

${ }^{4}$ Fryns JP, Kleczkowska A, Verresen H, Van den Berghe H. Germinal mosaicism in achondroplasia. A family with 3 affected siblings of normal parents. Clin Genet 1985;24:156-8.

5 Reiser VA, Pauli RM, Hall JG. Achondroplasia: unexpected familial recurrence. Am J Med Genet 1984;19:245-50.

6 Allanson JE. Germinal mosaicism in Apert syndrome. Clin Genet 1986;29:429-33.

${ }^{7}$ Hall JG, Dorst JP, Rotta J, McKusick VA. Gonadal mosaicism in pseudo achondroplasia. Am J Med Genet 1987;28:143-51.

${ }^{8}$ Hall JG, Byers PH. Genetics of tuberous sclerosis. Lancet 1987;ii:751.

Correspondence and requests for reprints to Dr $\mathrm{N}$ Philip, Centre de Génétique Médicale, Hôpital d'Enfants de la Timone, Boulevard Jean Moulin, 13385 Marseille Cedex 5, France. 